\title{
Heat Transfer and Thermographic Analysis of Catalyst Surface during Multiphase Phenomena under Spray-Pulsed Conditions for Dehydrogenation of Cyclohexane over Pt Catalysts
}

\author{
Rajesh B. Biniwale, ${ }^{\dagger, \ddagger}$ N. Kariya, ${ }^{\ddagger}$ H. Yamashiro, ${ }^{\S}$ and Masaru Ichikawa*, \\ National Environmental Engineering Research Institute, Nehru Marg, Nagpur 440020 India, \\ Catalysis Research Center, Hokkaido University, Sapporo 001-0021, Japan, and \\ Institute of Material Chemistry and Engineering, Kyushu University, Kasuga 816-8580, Japan
}

Received: October 12, 2005; In Final Form: December 8, 2005

\begin{abstract}
Dehydrogenation of cyclohexane over Pt/alumite and Pt/activated carbon catalysts has been carried out for hydrogen storage and supply to fuel cell applications. An unsteady state has been created using spray pulsed injection of cyclohexane over the catalyst surface to facilitate the endothermic reaction to occur efficiently. Higher temperature of the catalyst surface is more favorable for the reaction, thus the heat transfer phenomena and temperature profile under alternate wet and dry conditions created using spray pulsed injection becomes important. IR thermography has been used for monitoring of temperature profile of the catalyst surface simultaneously with product analysis. The heat flux from the plate-type heater to the catalyst has been estimated using a rapid temperature recording and thermocouple arrangement. The estimated heat flux under transient conditions was in the range of $10-15 \mathrm{~kW} / \mathrm{m}^{2}$, which equates the requirement for endothermic reactions to the injection frequency of $0.5 \mathrm{~Hz}$, as used in this study. The analysis of temperature profiles, reaction products over two different supports namely activated carbon cloth and alumite, reveals that the more conductive support such as alumite is more suitable for dehydrogenation of cyclohexane.
\end{abstract}

\section{Introduction}

There are efforts ongoing globally on hydrogen generation and utilization for fuel cells. Storage and supply of hydrogen from a centralized hydrogen production facility to fueling stations and on-board storage of hydrogen on fuel-cell vehicles are important aspects for successful implementation of hydrogenbased transportation. For this, hydrogen storage media are required to have relatively high hydrogen content on weight and volume basis. Another important requisite is to transport the hydrogen-containing media at close to atmospheric temperature and pressure conditions. Accordingly, much emphasis has been entrusted in developing systems for safe storage and transportation of hydrogen. Several studies include the development of materials such as metal hydrides,,${ }^{1,2} \mathrm{Mg}$ based alloys, ${ }^{3,4}$ carbon nanotubes, ${ }^{5,6}$ etc. The hydrogen storage capacity in terms of weight and volume basis is a major concern while developing these systems. One of the promising methods of storage and supply of hydrogen is through the catalytic reaction pair of dehydrogenation of cycloalkanes and subsequent hydrogenation of corresponding aromatic products. There are several merits of this system including the high volume (60 to $65 \mathrm{~kg}-\mathrm{H}_{2} \mathrm{~m}^{3}$ ) and weight (6 to $8 \mathrm{wt} \%$ ) basis capacity for hydrogen storage and that the reactants and products are recyclable and are suitable to transport at ambient temperature and pressure conditions due to their higher boiling temperatures. Since there is no requirement of heavy containers, such as in the case of high-pressure cylinders needed for carrying liquid hydrogen,

* Corresponding author. E-mail: michi@cat.hokudai.ac.jp. Tel: +8111-706-9140. Fax: +81-11-706-9139.

${ }^{\dagger}$ National Environmental Engineering Research Institute.

$\doteqdot$ Hokkaido University.

$\S$ Kyushu University. the effective content of hydrogen on the weight basis for cycloalkane systems is considerably higher.

Dehydrogenation of methylcyclohexane was reported by Newson et al., ${ }^{7}$ Klvana et al., ${ }^{8}$ and Grünenfelder et al. ${ }^{9}$ for seasonal storage of energy through storage and supply of hydrogen. Pt-based catalysts have been reported for highly selective dehydrogenation of cycloalkanes. Due to the endothermic nature of the dehydrogenation of cyclic hydrocarbons, chemical equilibrium is favored at higher temperature; the reactions are performed at high temperature under steady-state operations in gas phase. Hodoshima et al. proposed a liquidfilm state condition and conducted dehydrogenation of decalin over carbon-supported Pt-based catalysts. ${ }^{10,11}$ Kameyama and co-workers have used a non-steady spray pulse mode for dehydrogenation of 2-propanol on $\mathrm{Pt} / \gamma-\mathrm{Al}_{2} \mathrm{O}_{3}{ }^{12}$ Ichikawa and co-workers have reported high hydrogen production rates using wet-dry multiphase conditions in batch mode ${ }^{13}$ and using spray pulse reactor during dehydrogenation of cyclohexane and decalin over carbon-supported Pt catalysts. ${ }^{14,15}$ In another recent article, Hodoshima et al. have reported the use of a superheated liquid film reactor for enhancing the hydrogen evolution during dehydrogenation of decalin. ${ }^{16}$ It is evident from the above discussion that while using the liquid cycloalkanes for storage and supply of hydrogen its dehydrogenation on solid catalysts is facilitated and may be preferred under unsteady-state conditions.

We have reported earlier a considerable improvement in the yield of the reactions by feeding of atomized liquid reactant in pulses and alternatively creating wet and dry conditions on heated solid catalyst surfaces in the case of dehydrogenation of cyclohexane ${ }^{13,14}$ and reformation of isooctane. ${ }^{17}$ The alternate wet-dry conditions created on the catalyst surface facilitate the evaporation of liquid reactant on the catalyst surface. The 
evaporation of the reactant on catalyst surface enriches the catalyst surface with vapor-phase reactants and improves catalyst-reactant contact. The sudden expansion of volume of cycloalkanes due to phase change is approximately more than 100 times if calculated using ideal gas equation. This sudden increase in volume helps in purging the products and unreacted cycloalkanes from the catalyst surface. The easy removal of unreacted cyclohexane leaves back the cleaned catalyst at the end of the dry step. The unsteady-state using pulse-spray injection conditions to create alternate wet-dry conditions on the catalyst surface results in a high-frequency factor and shows severalfold increase in the reaction rate. The controlling factors to maintain the temperature of the catalyst surface under spraypulsed conditions are heat transferred to the catalyst surface, pulse injection frequency, and pulse width.

It is apparent from the above discussion that the transient conditions exist on the catalyst surface due to pulse injection of reactant spray and the phase change of the liquid reactant to vapor on the catalyst surface. It is necessary to maintain the reaction temperature on the catalyst surface, and the rate of the endothermic dehydrogenation reaction will depend on the thermal profile of the catalyst surface during injection mode. Thus, the heat transfer phenomena during multiphase reaction conditions and reaction dynamics are closely coupled. This prompted us to study the reaction dynamics and heat transfer on the catalyst surface by using IR thermography during cyclohexane dehydrogenation for possible further explanation of spray-pulsed reaction conditions. IR thermography is a powerful tool used to monitor the reaction kinetics following the change in temperature of catalyst surface during catalytic reactions. It has been used extensively in combinatorial chemistry for selection of the most active catalyst, generally in exothermic reactions. ${ }^{18-26}$ Also, the technique may be used for thermoneutral or even endothermic reactions. ${ }^{27}$ We have followed two different experimental methods for estimation of transient inlet heat flux to the catalyst using a conductive plate and then using an IR camera to record the temperature of the catalyst surface during reaction, leading to estimation of heat transfer phenomena of the multiphase reaction of dehydrogenation of cyclohexane over catalyst surface.

\section{Experimental Section}

2.1. Catalysts. The catalyst used in this study was Pt coated on alumite plate (Pt/alumite). We have also compared the thermal profile using activated carbon cloth (knit) as support for Pt catalyst (Pt/ACC). The catalyst was placed over the surface of a plate-type heater. The Pt supported on alumite $(\mathrm{Pt}$ loading $3 \mathrm{~g} \mathrm{~m}^{-2}$ ) was supplied by Research Institute of Aluminum Surface Technology, Japan, and the Pt supported on carbon cloth $(5 \mathrm{wt} \% \mathrm{Pt}$ ) was prepared in our laboratory using the method as described earlier. ${ }^{14}$

2.2. Methods. The dehydrogenation of cyclohexane (reaction 1) over Pt/alumite and Pt/ACC catalysts has been carried out using pulse-spray injection conditions. The experimental setup

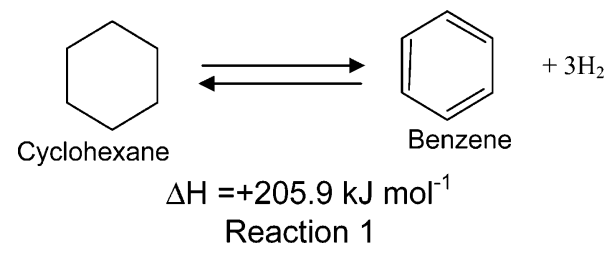

used for cyclohexane dehydrogenation to benzene and hydrogen using the spray pulse mode is shown in Figure 1. The

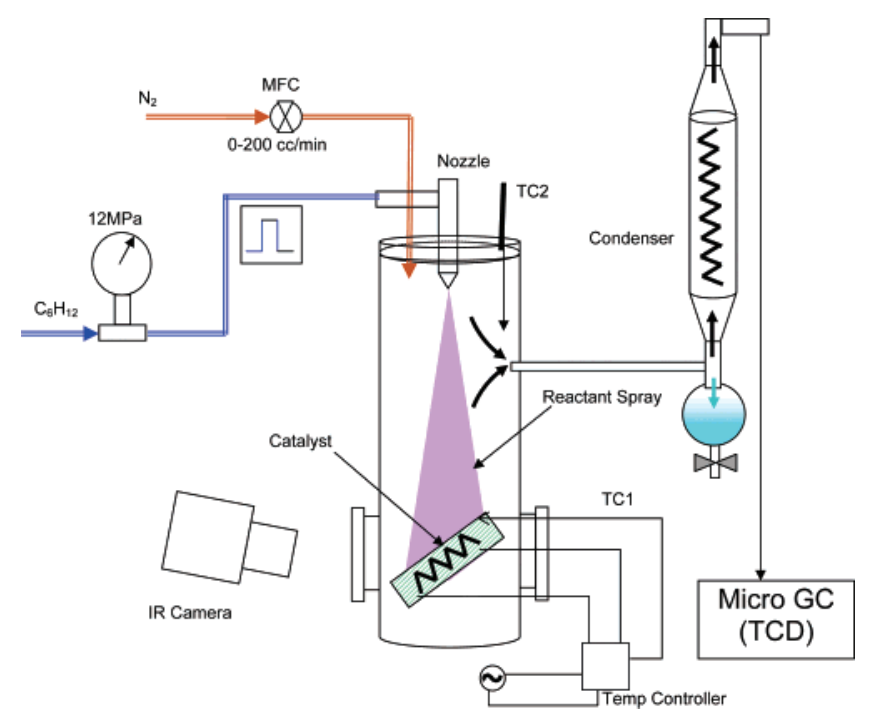

Figure 1. Experimental setup for spray-pulse type catalytic reactor system.

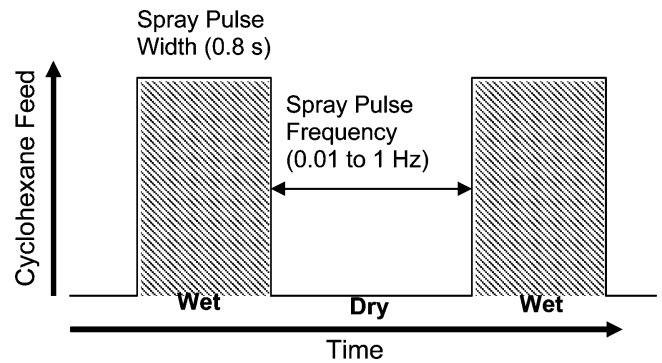

Figure 2. Schematic representation of pulse feeding of cyclohexane to the reactor.

experiments were targeted to monitor the temperature profile of catalyst surface and simultaneous product analysis under various operating conditions to facilitate understanding of the spray-pulse phenomenon. The main reactor was made of stainless steel equipped with a fine nozzle at the top for atomized injection of liquid reactant (cyclohexane). A pressure of $12 \mathrm{MPa}$ was maintained in the fuel supply line to generate atomized spray. Injection frequency was controlled using a frequency generator, and pulse injection width was kept constant at $0.8 \mathrm{~s}$. The modulation of pulse injection frequency to create alternate wet and dry conditions on catalyst surface is shown in Figure 2. The cyclohexane feed rate was varied from 4.46 to $446.67 \mu$ mol s${ }^{-1}$ by varying the pulse injection frequency from 0.01 to $1 \mathrm{~Hz}$. A carrier gas $\mathrm{N}_{2}$ was introduced from the top of the reactor. The catalyst was placed near the bottom of the reactor in tilted position with respect to the vertical axis of reactor and facing to a side watch glass window to allow the monitoring of the catalyst surface temperature by a noncontact thermal recorder. The catalyst was heated using a disk-type heater and the heating temperature was controlled at $250-300{ }^{\circ} \mathrm{C}$ using a temperature controller and thermocouple (thermocouple TC1 in Figure 1) arrangement. The unreacted cyclohexane and condensable products were collected in a reservoir connected to the condenser. The product analysis was carried out using a FID-GC (Shimadzu GC-14B, J\&W-DB-WAX, 30 m, column dia. $0.25 \mathrm{~mm}$, film $0.25 \mu \mathrm{m}$ ) and the gaseous products were periodically analyzed using a TCD micro GC (Agilent, molecular sieve $5 \AA, 10 \mathrm{~m}$ ).

2.3. Thermal Measurements during Spray Pulse Injection. The unsteady state created by injection of reactant spray in pulsed mode helps to improve the heat transfer on the catalyst surface by experiencing alternate wet and dry conditions. The 


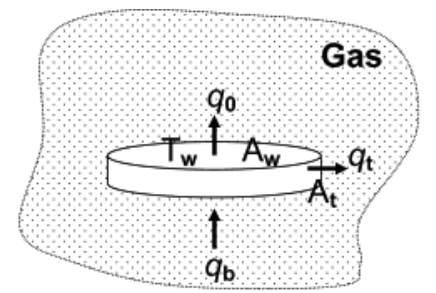

(a)

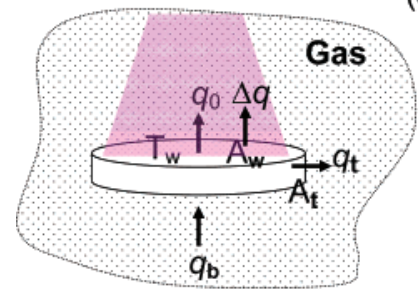

(b)

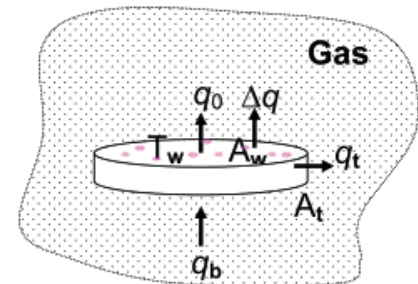

(c)
Figure 3. Heat balance on flat plate (a) steady state before pulse is arrived, (b) unsteady-state wet condition, and (c) unsteady-state drying.

alternate dry condition formed on the catalyst surface avoids the formation of liquid pools, which may cause resistance to heat and mass transfer during the reaction. Heat balance on a flat plate of thickness $t$ and the surface is heated at the temperature $T_{\mathrm{w}}$ and is shown in Figure 3. At the steady-state condition when there is no spray of reactant being injected, the heat balance as shown in Figure 3a may be written as eq 1:

$$
\left(q_{b}-q_{0}\right) A_{w}-q_{t} A_{t}=0
$$

where, $q_{b}$ is the heat flux provided to the flat plate by heater $\left(\mathrm{W} \mathrm{m}^{-2}\right), q_{0}$ is the heat flux from the top surface of the plate under natural convection $\left(\mathrm{W} \mathrm{m}^{-2}\right), q_{\mathrm{t}}$ is the heat flux from peripheral surface of the plate $\left(\mathrm{W} \mathrm{m}^{-2}\right), A_{\mathrm{w}}$ is the cross sectional area $\left(\mathrm{m}^{2}\right)$, and $A_{\mathrm{t}}$ is the peripheral area $\left(\mathrm{m}^{2}\right)$.

When atomized spray of liquid reactant is injected on the catalyst surface, a portion of heat is consumed in heating the liquid reactant and vaporizing it on the surface. An unsteady state is created on the flat plate and the heat balance may be denoted as in eq 2

$$
\left(q_{b}-q_{0}-\Delta q\right) A_{w}-q_{t} A_{t}=\rho c_{p} A_{w} \tau \frac{\partial T}{\partial t}
$$

From the equations 1 and 2, the portion of heat flux consumed during spray injection may be as follows:

$$
\Delta q=\rho c_{p} \tau \frac{\partial T}{\partial t}
$$

where $\rho$ is density $\left(\mathrm{kg} \mathrm{m}^{-3}\right), c_{p}$ specific heat capacity $\left(\mathrm{J} \mathrm{kg}^{-1}\right.$ $\left.\mathrm{K}^{-1}\right)$, and $\tau$ is thickness of the plate $(m)$.

Initially, the temperature gradient with respect to time and the heat flux $q_{b}$ in eqs 2 and 3 were experimentally determined. It was assumed that the evaporation of liquid reactant, the dehydrogenation reaction over catalyst surface, and subsequent removal of products and unreacted cyclohexane are completed before the arrival of the next pulse, i.e., within $1 \mathrm{~s}$ at the pulse injection frequency of $1 \mathrm{~Hz}$. Therefore, for estimation of transient temperature gradient, a high recording speed for temperature with reading at every $10 \mu$ s was used. Two type-K thermocouples of diameter $0.1 \mathrm{~mm}$ were used for the purpose of temperature measurement and were placed on an aluminum plate, one at the center (designated as point 'A'). The second thermocouple was placed on the inner concentric line at $15 \mathrm{~mm}$ radial distance from center of the plate (point ' $\mathrm{B}$ '). This

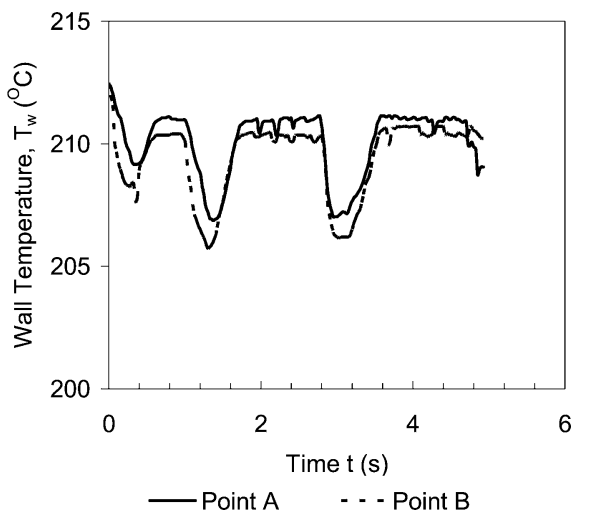

Figure 4. Transient temperatures measured on two different points on catalyst surfaces using thermocouples and data recorder.

aluminum plate with thermocouples is then placed on the flat heater inside a reactor. The voltage signal generated by the thermocouple in the range of 0 to $20 \mathrm{mV}$ corresponding to temperature of 0 to $500{ }^{\circ} \mathrm{C}$ was amplified using an amplifier and recorded. The inlet heat flux to catalyst mesh from heater was estimated by energy balance on a heater block.

The catalyst surface temperature profile during the pulse injection of cyclohexane was monitored using an infrared camera model Neo-Thermo TVS-8500 (provided by Nippon Avionics Co. Ltd). The frame rate of 60 frames per second has been used for recording temperature profile of the catalyst surface. The reading of temperatures by IR camera was calibrated by comparing with temperatures recorded by thermocouple at four different points. Emissivity correction was applied to record the surface temperature of the catalyst.

\section{Results and Discussion}

3.1. Inlet-Heat Flux to the Catalyst Surface. The rapid recording of the temperature of the aluminum plate equipped with thermocouples was made for monitoring of the change of temperature with respect to time under the pulse spray conditions. The apparent set temperature for the heater was $200{ }^{\circ} \mathrm{C}$, and the ambient gas temperature was observed to be $75^{\circ} \mathrm{C}$. The more the ambient gas temperature, the more the amount of cyclohexane getting evaporated before reaching to the catalyst surface. The ambient gas temperature increased with increase in the set heating temperature. Since our interest was to observe the heat transfer including the phase change of the reactant on the catalyst surface, the heating temperature was set near to 200 ${ }^{\circ} \mathrm{C}$ or less so as to keep ambient gas temperature below the boiling point of cyclohexane. The transient temperatures on the surface of the catalyst were recorded by using thermocouples and the results are shown in Figure 4. The rapid recordings of the temperatures were made for two different points A and B on the surface (thermocouples positioned as explained in section 3.2). It is clear that when the surface is clean and dries before the arrival of the first pulse of the spray of the cyclohexane the temperature difference experienced by the surface is comparatively higher than in the case of subsequent pulses and there exists an unsteady state.

The transient heat flux estimated when a single pulse of cyclohexane was injected over the metallic plate is shown in Figure 5. The heat flux estimated using eqs 2 and 3 was about 10 to $15 \mathrm{~kW} \mathrm{~m}{ }^{-2}$, at set temperature of $200{ }^{\circ} \mathrm{C}$. The phenomenon on the catalyst surface is accompanied by the phase change due to evaporation. The heat flux from the surface strongly depends on the variation in the liquid-solid contact ratio on the heat transfer area. Therefore, the heat flux is 


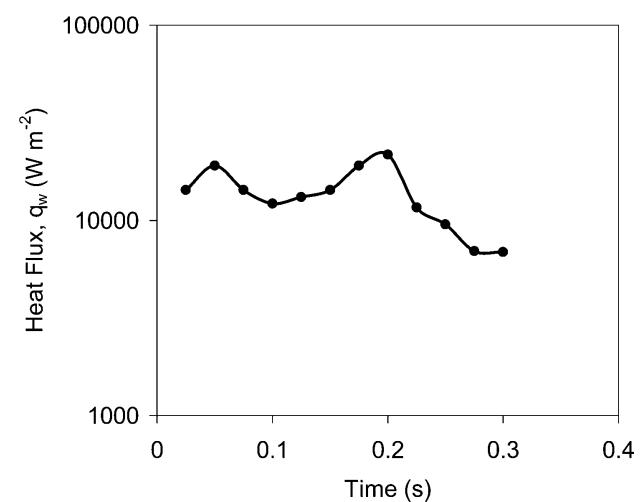

Figure 5. Estimated transient heat flux during the pulse injection of cyclohexane.

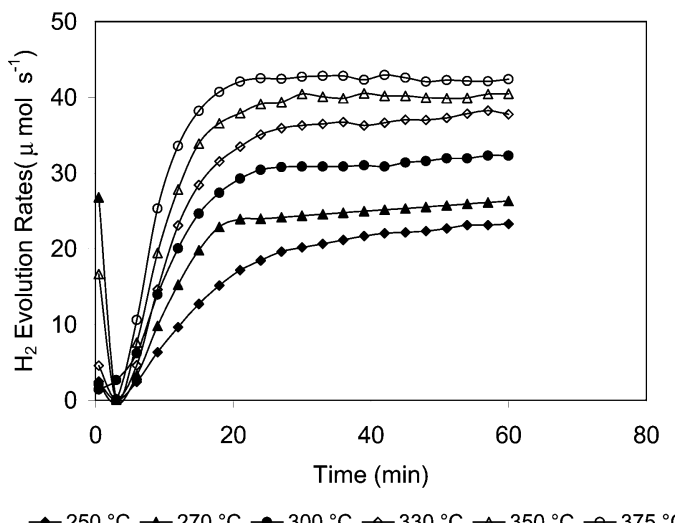

Figure 6. Hydrogen evolution rates over $\mathrm{Pt} /$ alumite catalyst at varying temperatures, cyclohexane feed rate $44.67 \mu \mathrm{mol} \mathrm{s}^{-1}$.

observed to be slightly fluctuating and higher heat flux indicates the increase in liquid-solid contact on the heated surface.

3.2. Effect of Temperature. The reaction of dehydrogenation of cyclohexane to benzene and hydrogen has been carried out at different heating temperatures from 250 to $375{ }^{\circ} \mathrm{C}$. The injection frequency of cyclohexane was kept constant at $0.1 \mathrm{~Hz}$ (corresponding to $44.67 \mu \mathrm{mol} \mathrm{s}^{-1}$ ). Figure 6 shows the time series data of hydrogen evolution rates over Pt supported on alumite ( $3 \mathrm{~g} \mathrm{~m}^{-2} \mathrm{Pt}$ loading) at varying temperatures. The rate of hydrogen evolution was observed to be increasing from 250 to $375^{\circ} \mathrm{C}$. The maximum rate of hydrogen evolution was ca. $41.67 \mu \mathrm{mol} \mathrm{s}{ }^{-1}$ at the temperature of $375{ }^{\circ} \mathrm{C}$. At $300{ }^{\circ} \mathrm{C}$ the hydrogen evolution rate was $31.67 \mu \mathrm{mol} \mathrm{s} \mathrm{s}^{-1}$. Since the dehydrogenation of cyclohexane is an endothermic reaction, the higher reaction temperature is more favorable. The higher reaction temperature also promotes rapid elimination of products benzene and hydrogen from catalyst surface, resulting in suppression of the reverse reaction. Desorption of benzene from the active sites is a rate-limiting step in this reaction, thus rapid desorption due to higher temperature and purging occurred by sudden volume expansion during evaporation helps in overcoming the rate-limiting step. The theoretical equilibrium conversion of cyclohexane over Pt catalyst may be about $30 \%$ and $92 \%$ at $250{ }^{\circ} \mathrm{C}$ and $300{ }^{\circ} \mathrm{C}$, respectively. Based on the $30 \%$ conversion obtained at heating temperature (may be designated as $T_{\mathrm{w}}$ ) of $300{ }^{\circ} \mathrm{C}$, it is apparent that the average temperature of catalyst surface may be in the range of $250{ }^{\circ} \mathrm{C}$. The thermal profile of the catalyst surface also reveals that the actual average temperature was lower than the heating temperature set for controlling electrical heater.

Conversion of cyclohexane to benzene was estimated using the FID-GC analysis of the condensed products after completion of the reaction. The conversion efficiency is generally observed

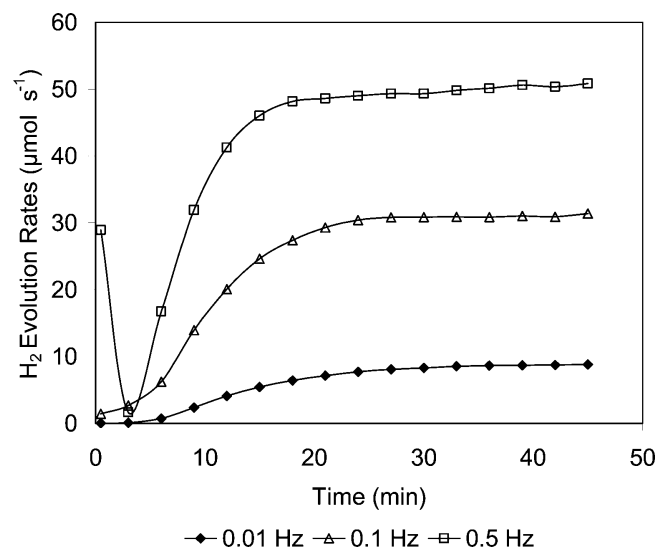

Figure 7. Variation in hydrogen evolution rates with increase in cyclohexane feed rates.

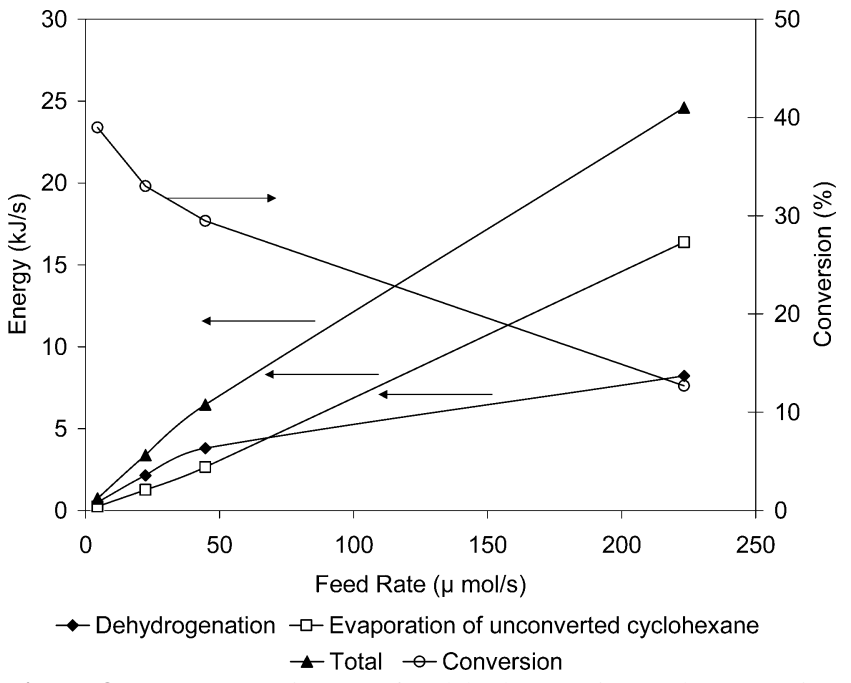

Figure 8. Energy requirement for dehydrogenation and evaporation of unreacted cyclohexane from catalyst surface with corresponding conversions at various feed rates.

to be increasing with increase in catalyst heating temperature. The condensed products contain cyclohexane and benzene. No other products such as partially dehydrogenated products (cyclohexene, methylcyclohexene) were observed. Also, no hydrocarbons were observed in the product gas. The selectivity of the catalyst for dehydrogenation of cyclohexane to produce hydrogen and benzene was observed to be nearly $100 \%$.

3.3. Effect of Cyclohexane Feed Rate. The rates of hydrogen evolution were observed to be dependent on cyclohexane feed rates. The feed rate of reactant was varied by changing the pulse injection frequency as $0.01,0.1$, and $0.5 \mathrm{~Hz}$. With increase in the feed rate of the reactant the hydrogen evolution rate was observed to be increasing at the heating temperature of $300{ }^{\circ} \mathrm{C}$. However, the increase in hydrogen evolution is not linear with feed rate. For example, change in feed rate by 50 -fold increased the the hydrogen evolution rate by about 5.7 times as shown in Figure 7. The conversion efficiency decreases with an increase in feed rate of cyclohexane; e.g., at the injection frequency of $0.01 \mathrm{~Hz}$ conversion efficiency was $39 \%$ and at $0.5 \mathrm{~Hz}$ the conversion was $12.7 \%$. However, at the heating temperature of $300{ }^{\circ} \mathrm{C}$ sufficient energy is available for evaporation of cyclohexane and for the dehydrogenation reaction. The energy required for evaporation and the dehydrogenation reaction was calculated at heating temperature of $300^{\circ} \mathrm{C}$ and at varying feed rates, as depicted in Figure 8. The energy requirement at various temperatures with feed rate of $44.67 \mu \mathrm{mol} \mathrm{s}^{-1}(0.1 \mathrm{~Hz})$ is shown in Figure 9. At the pulse injection frequency of $0.5 \mathrm{~Hz}$, 


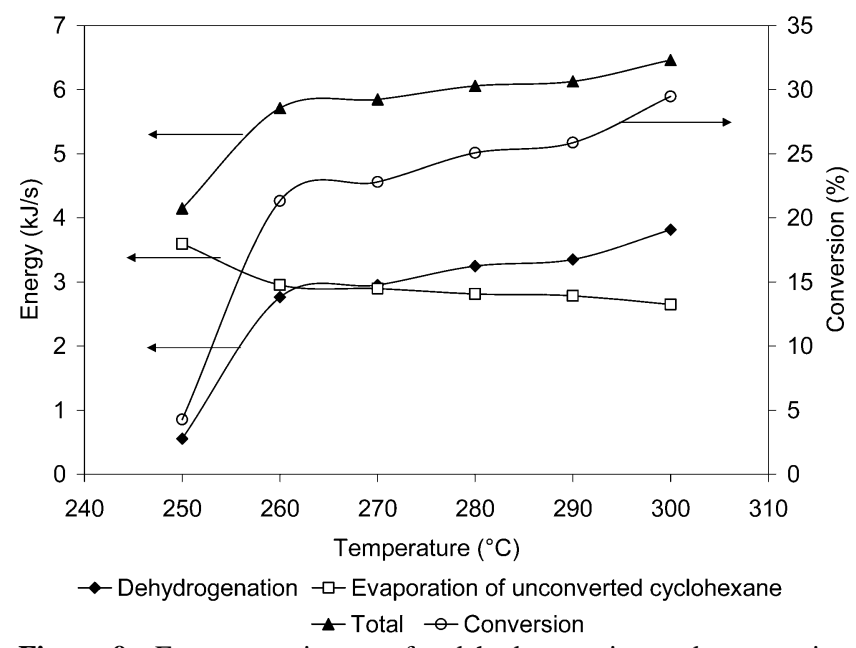

Figure 9. Energy requirement for dehydrogenation and evaporation of unreacted cyclohexane from catalyst surface with corresponding conversions at various temperatures.

considering the conversion efficiency of about $12.7 \%$, the energy requirement of dehydrogenation is $24.6 \mathrm{~J} \mathrm{~s}^{-1}$. At the same feed rate energy required for complete conversion of cyclohexane injected is $64.74 \mathrm{~J} \mathrm{~s}^{-1}$. The transient heat flux from plate-type heater to the catalyst was estimated to be about $10-15 \mathrm{~kW} \mathrm{~m}^{-2}$. This indicates that the heat provided to the catalyst was about 40.69-61.04 $\mathrm{J} \mathrm{s}^{-1}$. This energy is more than the total energy requirement for evaporation and dehydrogenation reaction for cyclohexane dose equivalent to $223.3 \mu \mathrm{mol} \mathrm{s}^{-1}$ corresponding to injection frequency of $0.5 \mathrm{~Hz}$. Therefore, increasing the pulse injection frequency to $0.5 \mathrm{~Hz}$ at heating temperature of $300{ }^{\circ} \mathrm{C}$ resulted in an increase in hydrogen production rates (Figure 7). Further increase in injection frequency to $1 \mathrm{~Hz}$ and with the same rate of conversion energy requirement is about $49.2 \mathrm{~J} \mathrm{~s}^{-1}$, which is more than the energy supplied by the heater at the lower levels of heat flux. The actual catalyst temperature may be still lower and the heat flux to catalyst surface may not be sufficient to provide required energy for evaporation of reactants and for endothermic dehydrogenation reaction. Nearly a liquid pool was formed on the catalyst surface and thus resulted in decrease in hydrogen production rate.

3.4. Temperature Profile during Pulse-Spray Injection. The thermal profile of the catalyst surface has been monitored during the unsteady state and equilibrium parts of the reaction at various operating conditions with respect to pulse injection frequency and bulk catalyst heating temperature. The temperature read by thermocouple TC1 (as shown in Figure 1) was used for monitoring and control of catalyst heating temperature, designated as $T_{\mathrm{w}}$. Temperature in void space designated as $T_{\mathrm{i}}$ in the reactor was monitored by thermocouple TC2. The temperature profile of catalyst surface was recorded using an IR camera with recording speed of 60 frames per second. The thermographs were generated at an interval of 10 frames each. Figure 10 shows the thermograph for the pulse injection frequency of $0.1 \mathrm{~Hz}, T_{\mathrm{w}}=300{ }^{\circ} \mathrm{C}$ and $T_{\mathrm{i}}$ observed was 115 ${ }^{\circ} \mathrm{C}$. The circular portion at the central part of the thermograph is catalyst surface and is the area of interest in the following discussions, whereas other portion at the periphery is of the reactor body, which is at lower temperatures. The histograms derived from the chronological IR images at $0.1 \mathrm{~Hz}$ and heating temperature of $300{ }^{\circ} \mathrm{C}$ are shown in Figure 11 and may be referred for further explanation of the behavior of the spraypulsed injection mode. At the initial time when reactant spray pulse had not arrived on the catalyst surface, the catalyst was under dry conditions with average surface temperature of 292

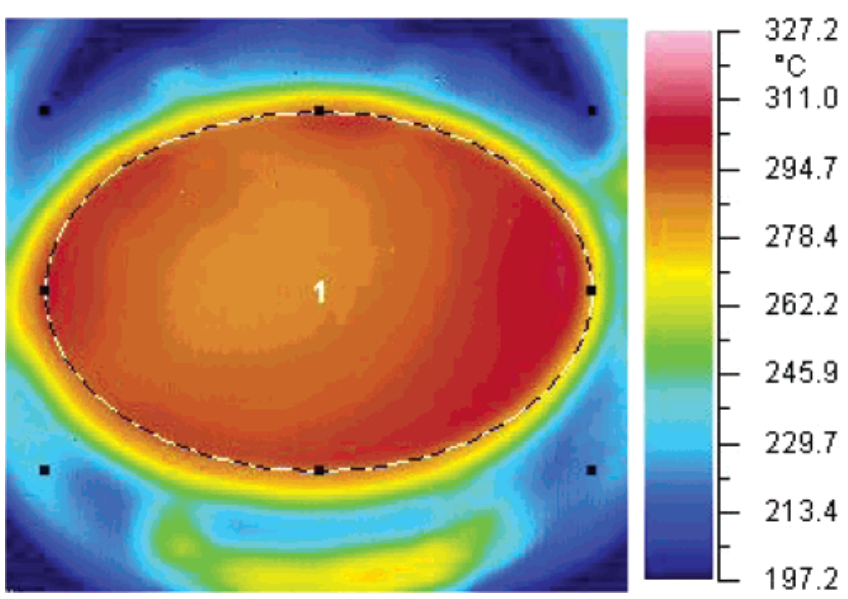

Figure 10. Thermograph of catalyst surface as recorded by infrared camera at set heating temperature of $300{ }^{\circ} \mathrm{C}$ and pulse injection frequency of $0.1 \mathrm{~Hz}$.

${ }^{\circ} \mathrm{C}$. The variability in local temperature of the catalyst surface was not very high, as seen from the histogram. When the first pulse was injected on catalyst surface $(t=0.0 \mathrm{~s})$, most of the catalyst was covered with liquid cyclohexane and temperature was lowered with major area of catalyst in the range of about $278{ }^{\circ} \mathrm{C}$ to $290{ }^{\circ} \mathrm{C}$. A part of the catalyst surface was in the range of $290{ }^{\circ} \mathrm{C}$ to $305{ }^{\circ} \mathrm{C}$. The broadening of the histogram peak indicates increased variability in local temperatures of catalyst surface. The variability in surface temperatures of the catalyst may be attributed two major reasons. First, the rate of evaporation may be different at different places because of flow of carrier gas, and due to introduction of cyclohexane on the catalyst surface there may be some variation in the emissivity depending on the contact between cyclohexane and catalyst. During the dry step (interval between two pulse injections), as time progresses the wet area gets reduced and the temperature of the most of the part of the catalyst increases. At $t=6.0 \mathrm{~s}$ the temperature reaches between 282 and $300{ }^{\circ} \mathrm{C}$ with a small portion at higher temperatures of about $305{ }^{\circ} \mathrm{C}$. The average temperature of catalyst surface was increased from $289^{\circ} \mathrm{C}$ at wet conditions to $292{ }^{\circ} \mathrm{C}$ at dry conditions at unsteady state. The overall and average temperature of the catalyst surface was observed to be increased at dry conditions at all frequencies. This explains the advantage of using the spray-pulsed injection mode for improving the catalyst activity. Since during dry conditions catalyst surface is free from the liquid reactant, its temperature is increased. The increased temperatures serve to keep the higher catalytic activity.

The void space temperature $T_{\mathrm{i}}\left(110\right.$ to $\left.115^{\circ} \mathrm{C}\right)$ was well above the boiling point of cyclohexane and thus there may be evaporation of considerable amount of cyclohexane from atomized spray before reaching to the catalyst surface. These vapors may be carried out by carrier gas as unreacted cyclohexane. With higher values of $T_{\mathrm{i}}$, the percentage of unreacted cyclohexane in products may increase.

The temperature profile of the catalyst surface at feed pulse injection frequency of $0.1 \mathrm{~Hz}$ and at steady state of the reaction after about $40 \mathrm{~min}$ (corresponding to more than 200 pulse injections) is shown in the histogram in Figure 12. When the reaction was continued and the catalyst was exposed to several injection pulses of the reactant, the temperature of almost all of the area of the catalyst was lowered to the average temperature of about $285^{\circ} \mathrm{C}$, with temperatures ranging between 275 and $295{ }^{\circ} \mathrm{C}$ during the dry conditions, i.e., when the pulse had not arrived. Subsequently, when the pulse had arrived $(t=$ $0.0 \mathrm{~s}$ ) and the catalyst surface was wet, the average temperature 

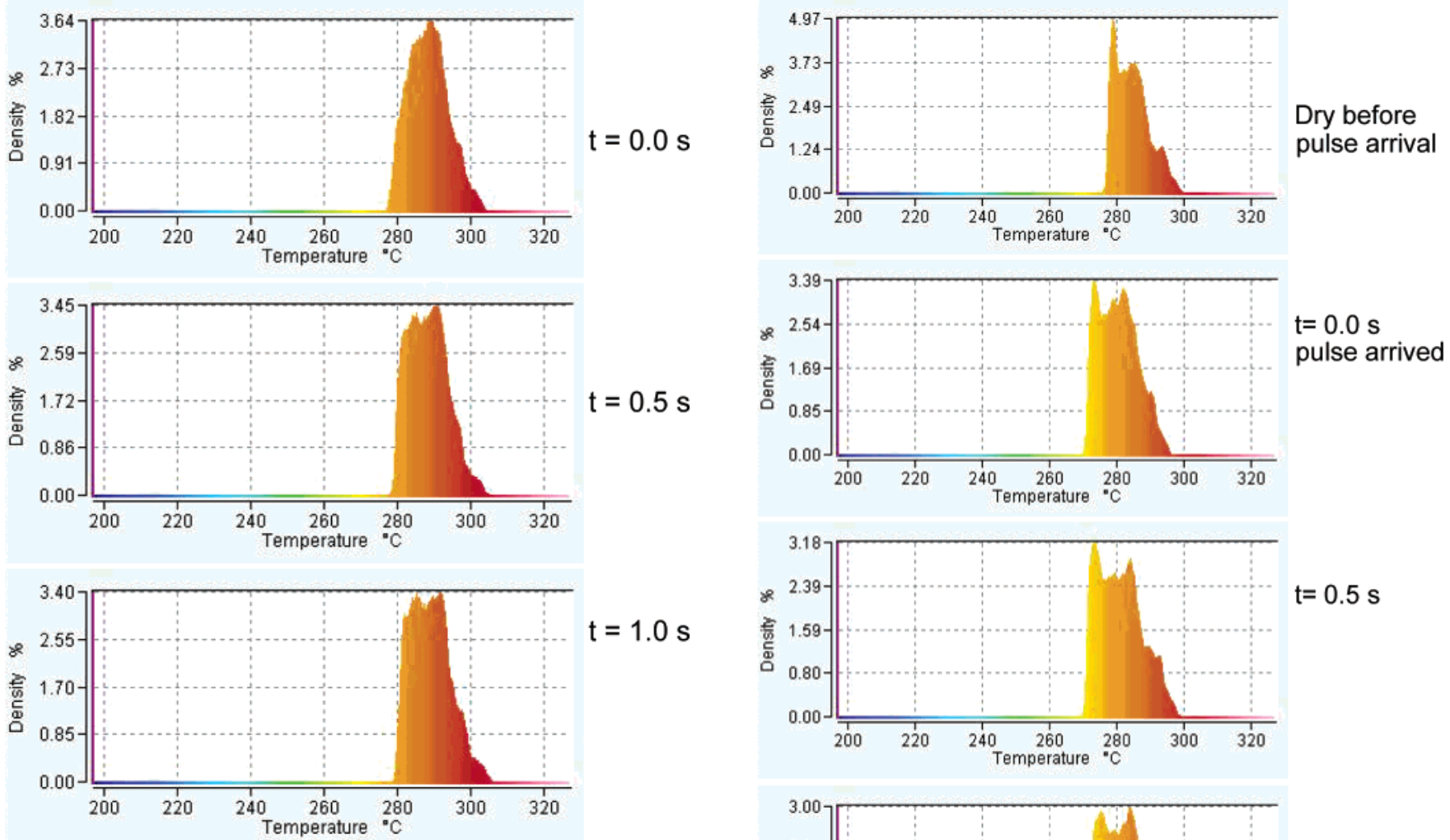

$t=0.5 \mathrm{~s}$
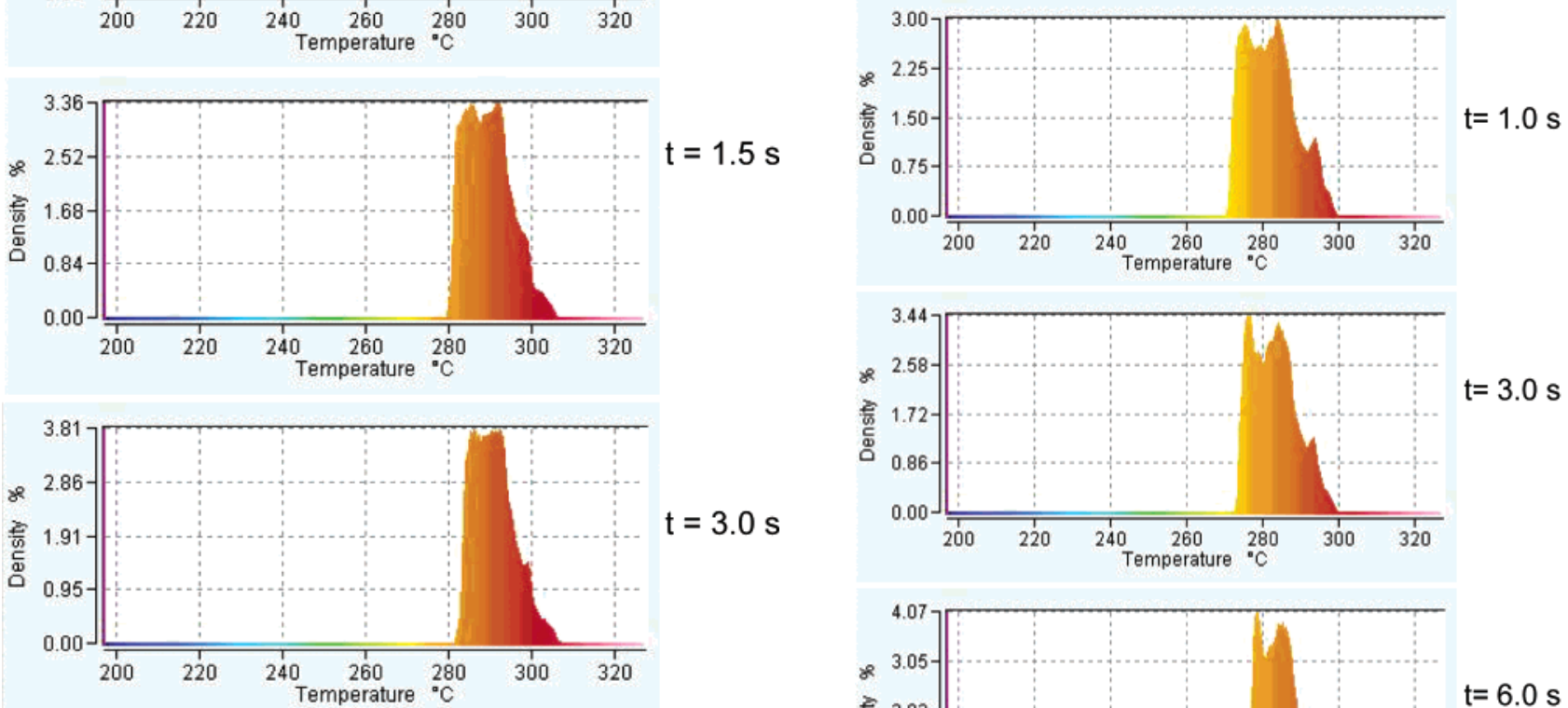

$t=3.0 \mathrm{~s}$

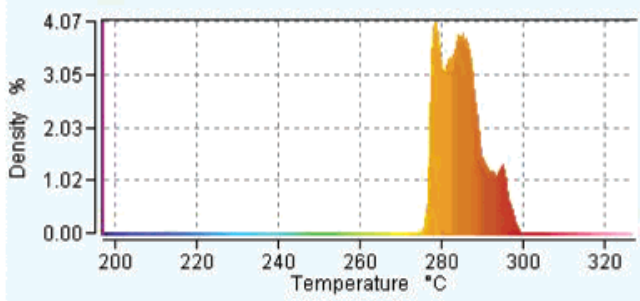

$t=6.0 \mathrm{~s}$

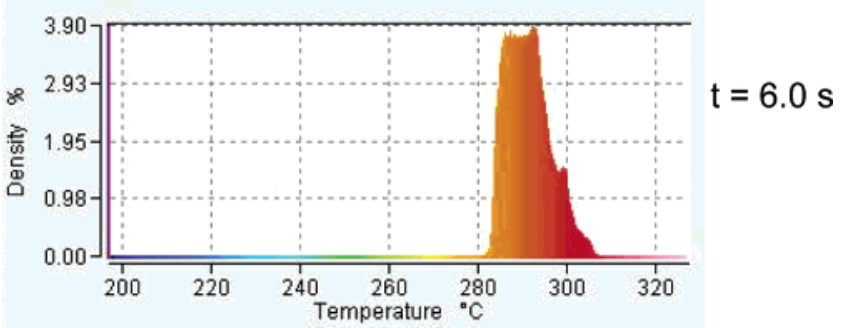

Figure 11. Histograms derived from chronological thermographic images at unsteady state, set heating temperature of $300{ }^{\circ} \mathrm{C}$, and pulse injection frequency of $0.1 \mathrm{~Hz}$.

was lowered to $281{ }^{\circ} \mathrm{C}$, whereas during dry conditions on the catalyst surface, the average temperature increased and was nearing to $285{ }^{\circ} \mathrm{C}$ (at $t=6.0 \mathrm{~s}$ ). The temperature of catalyst surface was observed to be on the lower side during steady state (about after $40 \mathrm{~min}$ ) as compare to unsteady state (the first few pulses). The lower temperatures of the catalysts (still well above

Figure 12. Histograms at steady state after $40 \mathrm{~min}$ from start of the pulse injection, set heating temperature of $300^{\circ} \mathrm{C}$, and pulse injection frequency of $0.1 \mathrm{~Hz}$.

the bp of reactant) in this condition may be forming a vapor phase of reactant at very close vicinity of the catalyst, and most of the time the reactant-catalyst contact was maintained, which results in the higher catalytic activity at steady state and maintaining the production rate of hydrogen.

The histograms at unsteady and steady state at the pulse injection frequency of $0.5 \mathrm{~Hz}$ and the heating temperature $T_{\mathrm{w}}$ at $300{ }^{\circ} \mathrm{C}$ are compared for variations in temperature profile (Supporting Information Figure $1 \mathrm{~S}$ and 2S, respectively). The variability in surface temperature increases at higher injection frequency $(0.5 \mathrm{~Hz})$ and surface temperatures are observed to 
be shifted toward lower side as compared to that at the injection frequency of $0.1 \mathrm{~Hz}$. During steady-state operation at $0.5 \mathrm{~Hz}$ the average dry condition temperature of catalyst was about 282 ${ }^{\circ} \mathrm{C}$. The average temperature was about $279{ }^{\circ} \mathrm{C}$ during wet conditions $(t=0.0 \mathrm{~s})$ and was recovered to about $282^{\circ} \mathrm{C}$ during relatively dry conditions $(t=1.5 \mathrm{~s})$. The next pulse and wet condition appears at $t=2.0 \mathrm{~s}$, corresponding to cyclic injection of reactant spray on catalyst surface. As at injection frequency of $0.5 \mathrm{~Hz}$, the reactant may have been always present on the catalyst surface, increasing the pulse injection frequency to 0.5 $\mathrm{Hz}$ resulted in increase in hydrogen production rate. At the frequency of $1 \mathrm{~Hz}$ there is a liquid pool formation on the catalyst surface and an accumulation of liquid reactant within reactor, therefore no reaction was carried out at frequencies higher than $0.5 \mathrm{~Hz}$. The trend observed at lower frequency of $0.01 \mathrm{~Hz}$ is similar to the $0.1 \mathrm{~Hz}$ with prolonged dry conditions.

The advantage of spray-pulsed mode injection of cyclohexane is demonstrated by reporting the reaction data and time-resolved temporal analysis of temperature of the catalyst surface that the multiphase condition is important for catalyst activity. Therefore, an increase in feed rate frequencies results in high hydrogen evolution rates until the multiphase phenomena exist on the surface.

3.5 Effect of Dry and Wet Conditions on Thermal Profile at Varying Set Temperatures. The shape of the thermal profile was recorded at different catalyst heating temperatures, particularly at $250,270,330$, and $350{ }^{\circ} \mathrm{C}$ at both dry and wet conditions. Figure 13 depicts a comparison of thermal profiles at dry and wet conditions at heating temperatures of 250 and $270{ }^{\circ} \mathrm{C}$, respectively. The shape of the thermal profile is more or less a bell shape with a broader profile at wet conditions. At the heating temperatures in dry and wet conditions, the temperature of surface is always lower than the set heating temperature. The average temperatures of $228^{\circ} \mathrm{C}$ (dry) and 225 ${ }^{\circ} \mathrm{C}$ (wet) were observed for heating temperature of $250{ }^{\circ} \mathrm{C}$, whereas for heating temperature of $270{ }^{\circ} \mathrm{C}$, the average surface temperatures at dry and wet conditions were observed to be $259^{\circ} \mathrm{C}$ and $255^{\circ} \mathrm{C}$, respectively.

At higher heating temperatures 330 and $350{ }^{\circ} \mathrm{C}$, the shape of the thermal profile was distinctly different than that at lower temperatures (Supporting Information Figure 3S). The thermal profile was nearly a vertical straight line on the lower temperature side for both dry and wet conditions. The average surface temperatures were close to the heating temperatures. The corresponding average surface temperatures at 330 and $350{ }^{\circ} \mathrm{C}$ were $324^{\circ} \mathrm{C}$ and $346^{\circ} \mathrm{C}$ at dry conditions. The peak broadening is less as compared to the lower temperatures, indicating more uniform heating of catalyst surface at higher temperatures. The uniform heating results in uniform rate of reaction over the catalyst surface and thus lead to higher hydrogen production.

3.6. Effect of Catalyst Support. We have also monitored the surface temperature profile for Pt supported on activated carbon cloth (Pt/ACC) during the same reaction of dehydrogenation of cyclohexane under spray-pulsed injection mode using the same reactor. When reactant is organic solvent, the carbon support is preferred due to its ability to wet by reactant, thus providing a good contact with catalyst. As there are no acid sites, the carbon formation during reaction is avoided. A conductive support (alumite) is preferred for uniform heating and for higher surface temperature. The hydrogen production rate and the temperature difference between the dry and the wet conditions on Pt/alumite and Pt/ACC catalysts at varying operating frequencies were compared as shown in Table 1 and Figure 14. The temperature at dry conditions was decreased with
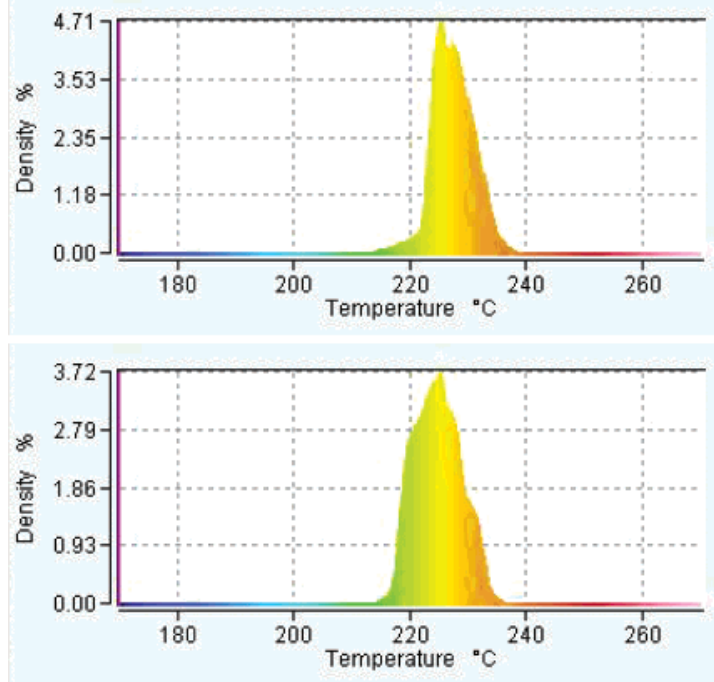

(b)

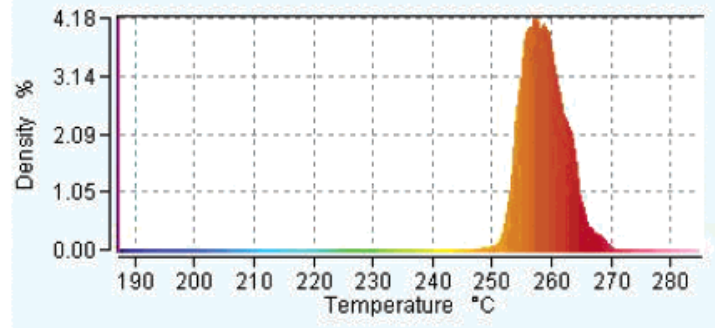

(c)

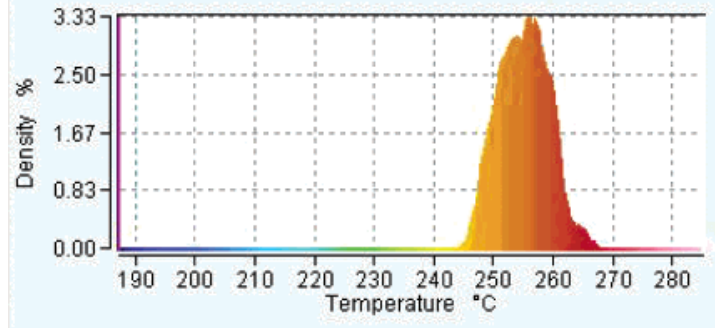

(d)

Figure 13. Comparison of thermal profile of dry and wet catalyst surface at lower temperatures, (a) $250{ }^{\circ} \mathrm{C}$ dry, (b) $250{ }^{\circ} \mathrm{C}$ wet, (c) 270 ${ }^{\circ} \mathrm{C}$ dry, and (d) $270{ }^{\circ} \mathrm{C}$ wet conditions, pulse injection frequency 0.1 $\mathrm{Hz}$.

TABLE 1: Comparison of Average Surface Temperatures and Hydrogen Production Rates over Different Catalysts

\begin{tabular}{cccccc}
\hline & \multicolumn{2}{c}{ Pt/alumite } & & \multicolumn{2}{c}{ Pt/ACC } \\
\cline { 2 - 3 } \cline { 5 - 6 } $\begin{array}{c}\text { set heating } \\
\text { temp }\left({ }^{\circ} \mathrm{C}\right)\end{array}$ & $\begin{array}{c}\text { avg surface } \\
\text { temp }\left({ }^{\circ} \mathrm{C}\right)\end{array}$ & $\begin{array}{c}\mathrm{H}_{2} \text { production } \\
\mathrm{m} \mathrm{mol} / \mathrm{g}_{\mathrm{p}} / \mathrm{s}\end{array}$ & & $\begin{array}{c}\text { avg surface } \\
\text { temp }\left({ }^{\circ} \mathrm{C}\right)\end{array}$ & $\begin{array}{c}\mathrm{H}_{2} \text { production } \\
\mathrm{m} \mathrm{mol} / \mathrm{g}_{\mathrm{pt}} / \mathrm{s}\end{array}$ \\
\hline 250 & 225 & 1.50 & & 212 & 0.20 \\
270 & 255 & 1.70 & & 248 & 1.05 \\
300 & 285 & 2.10 & & 257 & 1.21 \\
330 & 317 & 2.47 & & 285 & 1.65 \\
350 & 340 & 2.67 & &
\end{tabular}

an increase in injection frequency, whereas the hydrogen production rate per unit weight of the catalyst was observed to be increasing with injection frequency. The conversion efficiency was strongly dependent on the average temperature of the catalyst surface. At injection frequency of $0.1 \mathrm{~Hz}$ the difference between dry and wet conditions was about $29^{\circ} \mathrm{C}$ at steady state, which was maximum as compare to other pulse injection frequencies. Since the dehydrogenation of cyclohexane over Pt catalyst was observed to be highly selective, the energy consumption, which results in temperature decrease of catalyst, may be attributed to the energy required for evaporation of cyclohexane and dehydrogenation only. 


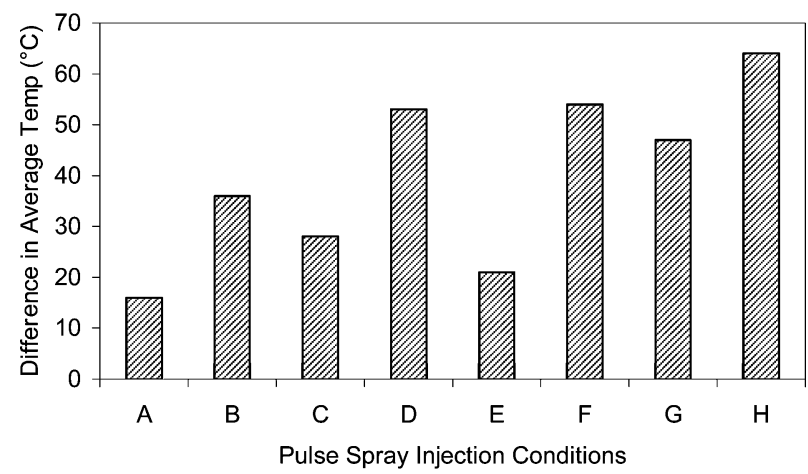

Figure 14. Difference between average surface temperatures of $\mathrm{Pt} /$ alumite and Pt/ACC catalysts at set heating temperature of $300{ }^{\circ} \mathrm{C}$ and various feed conditions, namely, (A) $0.1 \mathrm{~Hz}$, dry, unsteady, (B) 0.1 $\mathrm{Hz}$, wet, unsteady, (C) $0.1 \mathrm{~Hz}$, dry, steady, (D) $0.1 \mathrm{~Hz}$, wet, steady, (E) $0.5 \mathrm{~Hz}$, dry, unsteady, (F) $0.5 \mathrm{~Hz}$, wet, unsteady, (G) $0.5 \mathrm{~Hz}$, dry, steady, and $(\mathrm{H}) 0.5 \mathrm{~Hz}$, wet, steady.

When a more conductive support such as alumite is used for Pt catalysts, the average temperature and difference between average temperatures on two different supports at various operating conditions is shown in Figure 14. The loading of catalyst was nearly same for both of the catalysts at the reaction conditions. It was observed that in the case of both the supports the average temperature decreased from dry and unsteady state to wet unsteady, and further decreased at steady state as compared to unsteady state at the same injection frequency. An increase in the injection frequency from 0.1 to $0.5 \mathrm{~Hz}$ also resulted in decrease of average surface temperatures, since the reaction is highly selective and the decrease in temperature may be attributed to the energy required for evaporation and dehydrogenation of cyclohexane. There is increase in hydrogen production rates at steady state and at higher injection frequencies. However, the higher the temperature of the catalyst surface, the more favorable the reaction of dehydrogenation of cyclohexane. The more conductive support of alumite is suitable to keep surface temperature uniform and average temperature higher. Particularly, the difference between average temperatures on these two supports is higher at higher injection frequencies. Also, the hydrogen production rate observed using Pt/alumite catalysts is higher as compared to Pt/ACC catalysts.

\section{Conclusions}

The dehydrogenation of cyclohexane was carried out on Pt/ alumite and Pt/ACC catalysts using pulse spray reactor under transient conditions. The rate of hydrogen evolution was observed to be increasing with increase in reaction temperature $\left(250\right.$ to $\left.375{ }^{\circ} \mathrm{C}\right)$ or with an increase in the cyclohexane feed rate frequency $(0.01$ to $0.5 \mathrm{~Hz})$, particularly at heating temperature of $300{ }^{\circ} \mathrm{C}$. Therefore, it may be concluded that it is possible to optimize the spray pulsed reactor operating conditions for heating temperature and cyclohexane dose to obtain higher hydrogen production rates.

The temperature profiles of the catalyst surfaces studied using an IR camera during the pulse-spray injection of cyclohexane reveal that the actual temperature of the catalyst surface is much lower than that of the set heating temperature. It is clear from the decreased surface temperature observed that under the liquid pool conditions the catalyst efficiency may be lowered, whereas when dry conditions are generated by varying the injection frequency, the catalyst temperature is increased. This may help improve catalyst activity. Hence, the use of alternate wet and dry conditions by spray-pulse injection helps in achieving better catalyst activity. The lowering of the catalyst temperature in the case of endothermic reactions may be monitored by IR thermography and it may indicate the activity of the catalyst. Therefore, the use of IR thermography has been demonstrated for strongly endothermic reactions. This may be useful in timely research in the field of IR thermography for screening the catalysts for even strongly endothermic reactions. Better heat flux and the uniform temperatures on catalyst surface may be obtained using conductive support such as an alumite support, and such support is more suitable for the endothermic reaction of cyclohexane dehydrogenation.

The rate-limiting step of desorption of benzene from the active sites is overcome due to higher temperatures of surface and sudden volume expansion during evaporation of reactant on surface of the catalysts. This closely coupled heat transfer, multiphase phenomena with dehydrogenation reaction data used for optimization of conditions would be of interest to researchers working in this field. Since the change in surface temperature during the multiphase phenomena of spray pulsed condition and simultaneous dehydrogenation reaction was monitored using IR thermography, microkinetics was not considered.

Supporting Information Available: Figures 1S-3S. This material is available free of charge via the Internet at http:// pubs.acs.org.

\section{References and Notes}

(1) Singh, B. K.; Singh, A. K.; Srivastava, O. N. Int. J. Hydrogen Energy 1996, 21(2), 111-117.

(2) Muthukumar, P.; Prakash Maiya, M.; Srinivasa Murthy, S. Int. J. Hydrogen Energy 2005, in press.

(3) Singh, A. K.; Singh, A. K.; Srivastava, O. N. J. Alloys Compd. 1995, 227, 63

(4) Vijay, R.; Sunderesan, R.; Maiya, M. P.; Srinivasa Murthy, S. Int. J. Hydrogen Energy 2005, 30, 501-508

(5) Sankaran, A.; Kalaiselvan, M.; Ganesan, R.; Venuvanalingam, P.; Viswanathan, B. Bull. Catal. Soc. India 1 2002, 167.

(6) Viswanathan, B.; Sankaran, M.; Scibioh, M. A. Bull. Catal. Soc. India 2 2003, 12.

(7) Ali, J. K.; Newson, E. J.; Rippin, D. W. T.; Taube, P.; Taube, M. A. Adv. Hydrogen Energy 1981, 2, 1077-1085.

(8) Klvana, D.; Chaouki, J.; Kusohorsky, D.; Chavarie, C. Appl. Catal. 1988, $42121-130$.

(9) Grünenfelder, N. F.; Schucan, T. H. Int. J. Hydrogen Energy 1989, $14,579-586$.

(10) Hodoshima, S.; Arai, H.; Saito, Y. Int. J. Hydrogen Energy 2003, 28, 197-204.

(11) Hodoshima, S.; Arai, H.; Takaiwa, S.; Saito, Y. Int. J. Hydrogen Energy 2003, 28, 1255-1262.

(12) Kobayashi, I.; Yamamoto, K.; Kameyama, H. Chem. Eng. Sci. 1999, 54, 1319-1323.

(13) Kariya, N.; Fukuoka, A.; Ichikawa, M. Appl. Catal. A: General 2002, 233, 91-102.

(14) Kariya, N.; Fukuoka, A.; Utagawa, T.; Sakuramoto, M.; Goto, Y.; Ichikawa, M. Appl. Catal. A: General 2003, 247, 247-259.

(15) Biniwale, R. B.; Yamashiro, H.; Ichikawa, M. Catal. Lett. 2005, $102,1-2,23-31$.

(16) Hodoshima, S.; Takaiwa, S.; Shono, A.; Satoh, K.; Saito, Y. Appl. Catal. A: General 2005, 283, 235-242.

(17) Biniwale, R. B.; Mizuno, A.; Ichikawa, M. Appl. Catal. A: General 2004, 276, 169-177.

(18) Pawlicki, P. C.; Schmitz, R. A. Chem. Eng. Prog. 1987, 83(2), 40. 736.

(20) Kellow, J. C.; Wolf, E. E. Chem. Eng. Sci. 1990, 45(8), 2597-2602.

(21) Kellow, J. C.; Wolf, E. E. Catal. Today 1991, 9, 47-51.

(22) Qin, F.; Wolf, E. E. Ind. Eng. Chem. Res. 1995, 34, 2923-2930.

(23) Moates, F. C.; Somani, M.; Annamalai, J.; Richardson, J. T.; Luss, D.; Willson, R. C. Ind. Eng. Chem. Res. 1996, 35, 4801-4803.

(24) Taylor, S. J.; Morken, J. P. Science 1998, 280, 267-270.

(25) Holzwarth, A.; Schmidt, H. W.; Maier, W. F. Angew. Chem., Int Ed. 1998, 37(9), 2644-2647.

(26) Reetz, M. T.; Becker, M. H.; Kühling, K. M.; Holzwarth, A. Angew. Chem., Int. Ed. 1998, 37(9) 2647-2650.

(27) Reetz, M. T.; Becker, M. H.; Liebl, M.; Fürstner, A. Angew. Chem., Int. Ed. 2000, 39(7), 1236-1239. 